\title{
Análise Fatorial de Uma Medida de Estratégias de Enfrentamento
}

\author{
Eliane Maria Fleury Seidl ${ }^{1}$ \\ Bartholomeu T. Tróccoli \\ Célia Maria Lana da Costa Zannon \\ Universidade de Brasília
}

\begin{abstract}
RESUMO- O objetivo do estudo foi investigar a estrutura fatorial da Escala Modos de Enfrentamento de Problemas - EMEP, na versão adaptada para a população brasileira por Gimenes e Queiroz (1997), para mensurar estratégias de enfrentamento em relação a estressores específicos. A amostra foi composta por 409 adultos de ambos os sexos, onde 252 consideraram como estressor um problema atual que estivesse ocasionando estresse, enquanto 157 foram pessoas portadoras de enfermidades crônicas, que responderam à escala com base no problema de saúde que estavam apresentando. Foram extraídos quatro fatores pelo método dos eixos principais, rotação ortogonal: estratégias de enfrentamento focalizadas no problema, estratégias de enfrentamento focalizadas na emoção, práticas religiosas/pensamento fantasioso e busca de suporte social. A análise dos achados nas duas sub-amostras, diferenciadas quanto aos estressores dominantes, sugere possibilidades positivas de aplicação em contextos de pesquisa e de intervenção profissional, em especial a atuação clínica voltada para manejo do estresse junto a diferentes clientelas.
\end{abstract}

Palavras-chave: enfrentamento; estresse; estrutura fatorial.

\section{Factorial Analysis of a Coping Measure}

\begin{abstract}
ABSIRACT - The goal of this study was to investigate the factorial structure of the Brazilian version of the Ways of Coping Scale (Gimenes \& Queiroz, 1997) that measures coping strategies people use when facing specific stressors. The sample of 409 male and female adults was divided into two groups: 252 reported one major stressor related to a real problem in their everyday activities and the other 157 reported and described the suffering of a chronic disease. A factor analysis with principal axis method and orthogonal rotation, extracted four factors: coping strategies based on the stressor, coping strategies based on the emotion, religiosity/fantasy thinking and search for social support. Comparisons between the two samples suggested different possibilities for the development of research and intervention in the clinical work aimed at the management of stress by different type of patients.
\end{abstract}

Key words: coping; stress; factorial structure.

Estudos sobre os efeitos do estresse no processo saúdedoença vêm sendo desenvolvidos, desde que Hans Selye realizou pesquisas relacionadas à chamada síndrome de adaptação geral, em que a resposta de estresse foi caracterizada por reações fisiológicas do organismo, diante de demandas externas que prejudicavam a sua homeostase (Ferrero, Barreto \& Toledo, 1998). A partir dos anos 70, teorias psicológicas sobre o fenômeno estresse têm incorporado outras variáveis aos modelos explicativos, como a avaliação cognitiva (appraisal) e as respostas de enfrentamento (coping). Assim, a perspectiva teórica que concebe estresse e enfrentamento a partir da interação entre o organismo e seu ambiente tem tido destaque especial na área da psicologia da saúde (Lazarus, 1982; Kessler, Price \& Wortman, 1985).

No modelo interativo do estresse (stress transactional model), "enfrentamento refere-se aos esforços cognitivos e comportamentais voltados para o manejo de exigências ou demandas internas ou externas, que são avaliadas como sobrecarga aos recursos pessoais do indivíduo" (Folkman,

1 Endereço: Universidade de Brasília, Instituto de Psicologia, Campus Darcy Ribeiro. CEP: 70910-100. Brasília - DF. E-mail: seidl@unb.br.
Lazarus, Gruen \& De Longis, 1986, p. 572). Nessa teoria, dois aspectos ganham relevo: a avaliação cognitiva e o enfrentamento, que seriam mediadores entre o organismo e o ambiente, tornando essa transação um processo dinâmico e multidimensional.

As respostas ou estratégias de enfrentamento têm sido classificadas quanto à função em duas categorias: enfrentamento focalizado no problema e enfrentamento focalizado na emoção. No primeiro caso, a pessoa engajar-se-ia no manejo ou modificação do problema ou situação causadora de estresse, visando controlar ou lidar com a ameaça, o dano ou o desafio; são, em geral, estratégias ativas de aproximação em relação ao estressor, como solução de problemas e planejamento. O enfrentamento focalizado na emoção teria como função principal a regulação da resposta emocional causada pelo problema/estressor com o qual a pessoa se defronta, podendo representar atitudes de afastamento ou paliativas em relação à fonte de estresse, como negação ou esquiva. Essas estratégias não são necessariamente excludentes: diferentes estratégias de enfrentamento podem ser utilizadas simultaneamente para lidar com determinada situação estressora. Estudos têm identificado ainda outras estratégias de enfrentamento, como busca de suporte social, religiosidade e distração (Carver, Scheier \& Weintraub, 1989; Endler 
\& Parker, 1999; Vitaliano, Russo, Carr, Maiuro \& Becker, 1985).

Em suma, a concepção de enfrentamento no modelo interativo do estresse: (a) enfatiza os resultados adaptativos e não os aspectos psicopatológicos de possíveis respostas de enfrentamento; (b) valoriza as diferenças individuais, tanto na avaliação quanto na utilização das estratégias de enfrentamento; (c) compreende o enfrentamento no contexto da situação específica e das demandas particulares; (d) enfatiza a noção de processo e o seu caráter flexível, minimizando aspectos disposicionais ou de estilos de enfrentamento (Gimenes, 1997). Assim, essa conceituação difere daquelas que trabalham com a noção de estilos de enfrentamento, entendidos como características ou maneiras típicas da pessoa confrontar ou lidar com situações estressoras (Carver \& cols., 1989; Endler \& Parker, 1999).

Autores que concebem enfrentamento como respostas a eventos específicos reconhecem, no entanto, que determinadas estratégias de enfrentamento podem sofrer maior influência de características de personalidade, enquanto outras parecem sofrer maior influência de aspectos situacionais ou do contexto (Folkman \& cols., 1986).

Após mais de 30 anos de pesquisas, ainda parece haver divergências quanto a como identificar e medir o enfrentamento. Segundo Lazarus (1982), a avaliação do processo de enfrentamento deveria requerer instrumentos de medida bem diferentes dos que costumam ser utilizados por pesquisadores da área de personalidade, interessados na mensuração de traços ou estilos de enfrentamento. Nessa perspectiva, estudiosos do conceito têm preconizado a compreensão do que as pessoas fazem e/ou pensam diante de situações específicas que demandam esforços adaptativos, assim como o desenvolvimento de medidas sistematizadas, fidedignas e válidas, que captem a utilização das estratégias de enfrentamento em situações diversas ou ao longo de uma mesma situação (Amirkhan, 1990, 1994; Endler \& Parker, 1999).

Iniciativas no sentido de mensurar as estratégias de enfrentamento vêm sendo desenvolvidas, com alguns instrumentos construídos e validados para a utilização em diferentes contextos e em saúde, especialmente nos Estados Unidos, Canadá e Espanha (Amirkhan, 1990; Carver \& cols., 1989; Endler \& Parker, 1990, 1999; Folkman \& cols., 1986; Folkman \& Lazarus, 1985; Rodríguez-Marín, Terol, LópezRoig \& Pastor, 1992; Vitaliano \& cols., 1985).

Folkman e Lazarus, dois dos principais pesquisadores interessados no desenvolvimento teórico e empírico do conceito de enfrentamento, criaram o instrumento Ways of Coping Checklist - WCC, em 1980, que concebe o enfrentamento como respostas a estressores específicos. O instrumento tinha 68 itens, contendo itens que representavam estratégias voltadas para o problema e estratégias focalizadas na emoção. A resposta aos itens era do tipo sim ou não. Uma revisão realizada por Folkman e cols. (1986) levou à elaboração do Ways of Coping Questionnaire Revised - WOCQ$\mathrm{R}$, composto por oito fatores: confrontação, distanciamento, autocontrole, busca de suporte social, aceitação de responsabilidade, evitação-fuga, planificação de soluções e reavalia- ção positiva. Assim, as duas grandes categorias - focalização no problema e na emoção - desdobraram-se em diferentes fatores representando funções: alguns indicando uma ação direta em relação ao estressor (confrontação e planificação de soluções) ou de afastamento e de inibição da ação em relação ao estressor (distanciamento e evitação-fuga).

Vitaliano e cols. (1985), procedendo à análise da estrutura fatorial do Ways of Coping Checklist e a revisões teóricas do conceito, chegaram a um instrumento composto por 57 itens distribuídos em 5 fatores: focalização no problema, pensamento fantasioso/desiderativo, busca de suporte social, esquiva e autoculpa. O estudo de validação realizado junto à população norte-americana manteve os itens com cargas fatoriais superiores a 0,30 e a consistência interna das escalas obteve valores superiores a 0,70 . Posteriormente, $o$ instrumento foi revisado com a inclusão de mais três fatores - culpabilização de outros, religiosidade e pensamento positivo - sobre os quais não foram identificados indicadores de consistência interna e carga fatorial dos novos itens.

Em uma outra versão do instrumento de Vitaliano e cols., validada para a população espanhola por Rodríguez-Marín e cols.(1992), os valores dos alphas de Cronbach variaram de 0,40 a 0,76 , para os 11 fatores encontrados, índices muito baixos que indicam uma fragilidade quanto à consistência interna. A versão final espanhola ficou reduzida a 36 itens itens com carga fatorial menor que 0,40 foram excluídos distribuídos em cinco fatores, que representavam estratégias de enfrentamento de aproximação em relação ao estressor (focalização no problema, busca de apoio social, religiosidade, pensamento positivo e contabilização de vantagens) e seis fatores que representavam estratégias de afastamento ou de falta de ação em relação ao estressor (pensamento fantasioso/desiderativo, esquiva, autoculpa, culpabilização de outros, repressão emocional e resignação). Constata-se que a estrutura fatorial adotada no instrumento espanhol levou ao desdobramento de alguns fatores e à acentuada redução do número de itens (os fatores resignação, religiosidade e contabilização de vantagens tinham apenas dois itens), o que enfraqueceu o poder de análise do instrumento, do ponto de vista psicométrico. No entanto, a ampliação da escala de respostas para Likert de cinco pontos foi um aspecto positivo, contribuindo para a análise das diferenças das estratégias de enfrentamento.

Outras iniciativas voltadas para a construção de instrumentos para mensurar enfrentamento merecem ser mencionadas. Um instrumento citado freqüentemente na literatura é o COPE Inventory, elaborado por Carver e cols. (1989), que parte da concepção de que as respostas de enfrentamento são estáveis, não direcionadas a situações específicas. O COPE possui 14 fatores: enfrentamento ativo, reinterpretação positiva, planejamento, restrição ao enfrentamento, supressão de atividades competitivas, afastamento mental, afastamento comportamental, utilização de suporte social emocional, utilização de suporte social instrumental, aceitação, ventilação de emoções, busca da religiosidade, negação e uso de substâncias como álcool e drogas. Dados da análise da estrutura fatorial desse inventário apresentaram, no en- 
tanto, indicadores insatisfatórios como cargas fatoriais muito baixas (menores que 0,30 ) e cinco fatores com coeficientes de confiabilidade reduzidos (alphas variando de 0,68 a 0,45). Verificou-se ainda algumas intercorrelações elevadas entre fatores do COPE: enfrentamento ativo com planejamento $(r=0,85 ; p<0,001)$, enfrentamento ativo com supressão de atividades competitivas $(r=0,45 ; p<0,01)$ e suporte social instrumental com suporte social emocional $(r=0,88$; $p<0,001)$ (Clark, Bormann, Cropanzano \& James, 1995), indicando uma superposição acentuada desses fatores.

O Coping Strategies Indicator - CSI, construído e validado por Amirkham (1990), conceitua enfrentamento como resposta a situações específicas e possui três fatores: solução de problema, procura de suporte social e esquiva. O pesquisador lançou mão de análises dos fatores principais e fatorial confirmatória, em estudo realizado em quatro fases com amostras heterogêneas distintas. A estrutura fatorial com três fatores se manteve ao longo dos estudos com índices de consistência interna superiores a 0,70 , indicando boa estabilidade do instrumento.

Outra iniciativa foi a construção do Coping Inventory for Stressful Situations - CISS (Endler \& Parker, 1999), que resultou na identificação de três fatores, totalizando 48 itens: enfrentamento orientado para a tarefa, enfrentamento orientado para a emoção e esquiva (este último dividido em duas subescalas: distração e diversão social). Os pesquisadores canadenses trabalharam com carga fatorial superior a 0,40 para a inclusão dos itens nos fatores e os coeficientes de consistência interna alcançaram índices satisfatórios, variando de 0,90 a 0,74 .

Esses estudos, de construção e validação de instrumentos para avaliação do enfrentamento, ilustram o interesse em relação ao construto, bem como sua aplicação para melhor compreensão e intervenção nos processos psicológicos. No entanto, a literatura ainda indica a presença de debilidades metodológicas, como medidas inadequadas do ponto de vista psicométrico, estruturas fatoriais não investigadas e ausência de validação de instrumentos para populações específicas (Clark \& cols., 1995).

No Brasil, algumas iniciativas também merecem ser mencionadas. Tróccoli e colaboradores (Nunes, Tróccoli, Tamayo \& Pinheiro, 1999; Pinheiro, Tamayo \& Tróccoli, 2000; Tróccoli, 1998; Tróccoli, no prelo-a; Tróccoli, no prelo-b; Tróccoli, Laros, Moraes, Hostensky \& Araújo, 2000; Tróccoli, Nunes \& Rodrigues, 1999) traduziram e adaptaram a versão reduzida do Constructive Thinking Inventory CTI-S desenvolvido por Epstein seguindo a sua Teoria do Self Cognitivo-Experiencial (Epstein, 1990). De acordo com esta teoria, as pessoas diferem no grau e na eficácia quanto ao uso do pensamento racional versus pensamento experiencial. Para a maioria dos indivíduos, ocorre a predominância no uso de um sistema sobre o outro, bem como grandes diferenças quanto à habilidade para utilizar o sistema experiencial na resolução de problemas e adaptação ao estresse. Quanto maior for esta habilidade, maior o pensamento construtivo, isto é, mais eficazes são as estratégias de enfrentamento características da pessoa. Segundo esta proposição, portanto, o enfrentamento está associado à qualidade e ao tipo de uso do sistema experiencial humano.

Outra iniciativa desenvolvida no Brasil foi a tradução e adaptação para o português da escala de Vitaliano e cols. (1985), por Gimenes e Queiroz (1997), utilizando procedimentos de análise semântica e tradução reversa, sem, no entanto, proceder à investigação da sua estrutura fatorial. A Escala Modos de Enfrentar Problemas foi concebida com base no modelo interativo do estresse e conceitua enfrentamento como um conjunto de respostas específicas para determinada situação estressora. É de se esperar que a sua estrutura fatorial também decorra de algumas das características culturais refletidas nesse processo interativo. A possibilidade de replicação de algumas das dimensões originais, e/ ou acréscimo de outras dimensões, passa a ser parte fundamental tanto da adaptação da escala quanto da investigação da natureza dos modos de enfrentamento no nosso ambiente cultural em geral e para populações específicas em particular.

O objetivo do presente estudo foi, portanto, investigar a estrutura fatorial da Escala Modos de Enfrentamento de Problemas - EMEP (Vitaliano \& cols., 1985), para mensurar as estratégias de enfrentamento em relação a estressores específicos. Foi analisada a versão adaptada por Gimenes e Queiroz (1997) modificando-se apenas a escala de respostas (Likert de 4 pontos) substituída por escala de 5 pontos, à semelhança da versão espanhola (Rodrigues-Marin \& cols., 1992).

\section{Método}

\section{Amostra}

A amostra final foi composta por 409 adultos, homens e mulheres, agrupados em duas sub-amostras: A - 252 pessoas, contatadas em diferentes instituições de ensino e locais de trabalho, que responderam ao instrumento considerando como estressor uma situação ou problema atual que estivesse ocasionando estresse; $\mathrm{B}-157$ pessoas portadoras de enfermidades crônicas, contatadas em um hospital geral público e em um serviço privado especializado em fisioterapia para problemas do aparelho locomotor, que responderam à escala considerando como estressor o problema atual de saúde que estavam apresentando.

O perfil sóciodemográfico da amostra indicou que 61,6\% das pessoas eram do sexo feminino. A idade variou de 17 a 75 anos, sendo que a média foi de 34 anos $(D P=13,03)$. No que se refere à escolaridade, $29,4 \%$ tinham até o $1^{\circ}$ grau completo, $30,1 \%$ até o $2^{\circ}$ grau completo e $40,6 \%$ o curso superior incompleto e completo. Quanto à situação conjugal, 48,2\% eram casados ou viviam em união consensual, $43 \%$ eram solteiros e $8,8 \%$ eram separados, divorciados ou viúvos, vivendo sem parceiro(a).

As amostras A e B apresentaram perfil sóciodemográfico semelhante, com maioria de mulheres em ambas, sendo $57,1 \%$ na $\mathrm{A}$ e $68,8 \%$ na amostra B. O grupo de pessoas portadoras de doenças crônicas foi mais velho $(M=41$ anos; amplitude $18-75$ anos; $D P=13,8)$. Na amostra $\mathrm{A}$, a média de idade foi igual a 30 anos $(D P=10,6$; amplitude $17-59$ 
anos). A amostra composta por pessoas portadoras de doenças crônicas apresentou distribuição mais homogênea quanto à escolaridade: $30,3 \%$ tinham até o $1^{\circ}$ grau completo, $33,1 \%$ até o $2^{\circ}$ grau completo e $28,6 \%$ tinham até o nível superior completo. A amostra A teve $23,8 \%$ com $1^{\circ}$ grau incompleto e completo, 28,2 com escolaridade até o $2^{\circ}$ grau completo e $48,1 \%$ com superior incompleto ou completo. Os solteiros predominaram na amostra A $(53,8 \%)$, seguidos de casados ou pessoas vivendo em união consensual $(39,4 \%)$; na amostra B, os casados/união consensual foram maioria $(61,8 \%)$, seguidos de solteiros $(25,5 \%)$.

Os estressores mencionados pela sub-amostra A, em relação aos quais as estratégias de enfrentamento estavam sendo utilizadas, foram categorizados, obtendo-se a seguinte distribuição: problemas financeiros $(21,8 \%)$, problemas familiares $(21,7 \%)$, dificuldades pessoais como impedimentos para a concretização do projeto de vida e insatisfação consigo mesmo $(18,7 \%)$, problemas profissionais ou ligados ao trabalho $(18,3 \%)$, dificuldades conjugais ou amorosas $(6 \%)$, estressores do cotidiano, tais como problemas de transporte e excesso de ruído $(3,6 \%)$, falta de tempo para si $(3,2 \%)$, problemas de saúde de pessoa da família $(2,4 \%)$, dificuldades nas relações interpessoais $(1,6 \%)$ e estressores múltiplos de diferentes naturezas $(10,3 \%)$.

\section{Instrumento}

A versão adaptada por Gimenes e Queiroz (1997) da Escala Modos de Enfrentamento de Problemas (Vitaliano \& cols. 1985), composta por 57 itens, foi o instrumento investigado quanto à estrutura fatorial. Possui oito sub-escalas que expressam cognições (ações intrapsíquicas) e comportamentos (ações diretas) para lidar com eventos estressantes: focalização no problema (15 itens), pensamento positivo (6 itens), busca de apoio social (6 itens), religiosidade (3 itens), esquiva (10 itens), pensamento fantasioso/desiderativo (8 itens), autoculpa (3 itens) e culpabilização de outros (6 itens). As respostas foram dadas em uma escala tipo Likert de cinco pontos ( 1 = Eu nunca faço isso; $2=\mathrm{Eu}$ faço isso um pouco; 3 = Eu faço isso às vezes; 4 = Eu faço isso muito; 5 = Eu faço isso sempre).

Dados sóciodemográficos foram levantados mediante questões fechadas sobre as variáveis sexo, data de nascimento, escolaridade e situação conjugal.

\section{Procedimento}

O instrumento foi auto-administrado, sendo que apenas pessoas com escolaridade mínima equivalente à $3^{\mathrm{a}}$ série do primeiro grau foram incluídas. Após a informação sobre os objetivos do estudo, a apresentação por escrito do consentimento informado - com os esclarecimentos referentes ao anonimato e ao sigilo - e a obtenção do consentimento verbal, os participantes foram orientados quanto ao preenchimento do instrumento. Foi garantido o caráter voluntário da participação, bem como o respeito aos preceitos éticos que regem a realização de pesquisas com seres humanos em saúde (Ministério da Saúde, 1997).

Os participantes da amostra de pessoas acometidas por doenças crônicas (sub-amostra B) foram abordados em ambulatórios de diferentes especialidades (reumatologia, endocrinologia/diabetes, doenças cardiovasculares e cardiologia) de um hospital público de Brasília e em um serviço privado para problemas diversos da área motora onde faziam fisioterapia. Enquanto estavam em salas de espera, aguardando as consultas correspondentes, as pessoas foram orientadas a responder ao instrumento, após aceitarem participar do estudo.

A instrução foi feita mediante texto escrito, que era lido em voz alta pelo pesquisador, enquanto o participante acompanhava a leitura do mesmo. O conteúdo das instruções foi o seguinte:

As pessoas reagem de diferentes maneiras a situações difíceis ou estressantes. Para responder a este questionário, pense sobre como você está lidando com a sua enfermidade neste momento do seu tratamento. Concentre-se nas coisas que você faz, pensa ou sente para enfrentar esta condição, no momento atual. Escreva qual é a enfermidade que você possui:

Após o paciente escrever o nome da enfermidade, era apresentado um exemplo ("eu estou buscando ajuda profissional para enfrentar o meu problema"), que não constava do conjunto de 57 itens, com a escala de Likert de cinco pontos para instruir a pessoa na resposta. O texto continuava:

\begin{abstract}
Você deve assinalar a alternativa que corresponde melhor ao que você está fazendo quanto à busca de ajuda profissional para enfrentar o seu problema de saúde. Se você não está buscando ajuda profissional, marque com um $\mathrm{X}$ ou um círculo o número 1 (Nunca faço isso); se você está buscando sempre esse tipo de ajuda, marque o número 5 (Eu faço isso sempre). Se a sua busca de ajuda profissional é diferente dessas duas opções, marque 2, 3 ou 4, conforme ela está ocorrendo. Não há respostas certas ou erradas. O que importa é como você está lidando com a situação. Pedimos que você responda a todas as questões, não deixando nenhuma em branco. Obrigada pela participação.
\end{abstract}

Tendo assegurado de que a pessoa tinha compreendido as instruções, o pesquisador informava que se afastaria durante o preenchimento e que retornaria ao término do mesmo. No final, o pesquisador folheava o questionário visando identificar a existência de itens em branco; nesse caso, entregava o questionário para que o próprio paciente o assinalasse no campo específico.

Os integrantes da sub-amostra A foram convidados a participar do estudo em diferentes locais de trabalho (órgãos públicos e lojas comerciais) e de ensino (turmas de uma faculdade particular e turmas de ensino supletivo de escola pública do Distrito Federal). O procedimento foi semelhante ao utilizado em relação à sub-amostra $\mathrm{B}$ de pacientes crônicos. As instruções diferiram no seguinte: 
As pessoas reagem de diferentes maneiras a situações difíceis ou estressantes. Pense em uma situação ou problema atual que esteja produzindo estresse para você. Escreva aqui esta situação ou problema: Para responder ao questionário, tenha em mente as coisas que você faz, pensa ou sente para enfrentar esta condição, no momento atual. Em seguida foi apresentado o mesmo exemplo e os procedimentos adotados foram idênticos.

No final do instrumento foi incluída uma questão aberta, para as duas sub-amostras, cuja resposta era opcional, indagando "Você tem feito alguma outra coisa para enfrentar ou lidar com esta situação?". O objetivo foi identificar outras estratégias de enfrentamento que porventura estariam sendo utilizadas.

\section{Resultados}

Análises preliminares das variáveis indicaram a presença de dados faltosos nos 57 itens da escala, mas em percentual muito reduzido. O item com maior número de faltas teve $3,4 \%$ desses dados, sendo que a maioria dos itens não passou de $1 \%$. Estes foram substituídos pela média do respectivo item. A análise das freqüências e da distribuição das 57 variáveis indicou índices satisfatórios quanto à dispersão e à curtose, bem como a não existência de casos discrepantes (outliers) univariados. Gráficos de dispersão entre pares de variáveis não revelaram nenhum problema de ausência de linearidade.

A amostra inicial tinha 419 participantes. Com base no critério da distância Mahalanobis para $\chi^{2}=99,607 p<0,001$ (Tabachnick \& Fidell, 1996), foram identificados 6 casos na sub-amostra A e 4 casos na sub-amostra B como outliers multivariados sendo, então, excluídos, ficando a amostra final com 409 pessoas.

Inicialmente foi realizada a extração dos componentes principais, quando se verificou a adequação da matriz correlacional quanto aos pressupostos necessários à análise multivariada, como a ausência de multicolinearidade e a fatorabilidade dos dados. O indicador KMO foi igual a 0,806.

Com base no gráfico scree plot e considerando os eigenvalues acima de 2, decidiu-se pela extração de quatro fatores pelo método dos fatores principais (principal axis factoring), rotação ortogonal varimax. Apenas itens com carga fatorial superior a 0,35 (positiva ou negativa) foram incluídos nos fatores. A consistência interna dos fatores foi analisada pelo Alpha de Cronbach.

Os mesmos procedimentos para análise da estrutura fatorial do instrumento foram adotados em relação às duas sub-amostras ( $A=252$ e $B=157)$, separadamente, sendo que os achados foram muito semelhantes aos resultados obtidos na investigação com a amostra total. A solução fatorial apontou para o mesmo número de fatores, com eigenvalues maior que 2, com distribuição dos itens nos fatores muito semelhante à encontrada para a amostra total. Este achado reforça a solução encontrada, mostrando que a escala apresenta uma estabilidade adequada independente do tipo de estressor que levou às respostas de enfrentamento.
A solução fatorial dos quatro fatores encontrados (explicando $25,7 \%$ da variância total) com os respectivos itens, cargas fatoriais, comunalidades, percentual de variância explicada e Alpha de Cronbach estão apresentados na Tabela 1 . A escala validada ficou com 45 itens, que alcançaram carga expressiva em apenas um dos fatores. Os 12 itens excluídos tiveram carga inexpressiva em mais de um fator ou não atingiram a carga mínima exigida.

O Fator 1 ( 18 itens; $\alpha=0,84$ ) agrupou itens dos fatores originais focalização no problema e pensamento positivo, explicando 9,2\% da variância. Seus itens representam condutas de aproximação em relação ao estressor, desempenhadas pelo indivíduo, no sentido de solucionar o problema, lidar ou manejar a situação estressora (Ex: Encaro a situação por etapas, fazendo uma coisa de cada vez). Inclui também itens que envolvem esforços ativos eminentemente cognitivos voltados para a reavaliação do problema (reestruturação cognitiva), percebendo-o de modo positivo (Ex: Eu levo em conta o lado positivo das coisas).

O item "aceito a simpatia e a compreensão de alguém", na escala original incluído no fator busca de suporte social, migrou para este primeiro Fator. A análise semântica do item indica uma atitude favorável e de receptividade ao apoio social disponibilizado por terceiros, diferente dos comportamentos de procura de suporte social, típicos do quarto fator encontrado (busca de suporte social).

Outro item que migrou para o Fator 1 foi "desejo ser uma pessoa mais forte e otimista", que estava classificado na escala original como pensamento fantasioso/ desiderativo. Considerando que este item alcançou carga fatorial de 0,40 , recomenda-se que em aplicações futuras da escala o verbo desejar, que pode significar apenas a vontade de ser forte e otimista, seja substituído pelo verbo tentar (Ex: Tento ser uma pessoa mais forte e otimista), em consonância com uma postura mais ativa diante de situações difíceis, compatível com o significado do presente Fator. Sugere-se que o Fator 1 seja denominado estratégias de enfrentamento focalizadas no problema.

O segundo Fator ( 15 itens; $\alpha=0,81 ; 7,5 \%$ de variância explicada), denominado estratégias de enfrentamento focalizadas na emoção, agrupou itens dos fatores originais esquiva, pensamento fantasioso/desiderativo, autoculpa e culpabilização de outros. Incluiu itens referentes a reações emocionais negativas como raiva ou tensão (Ex: Demonstro raiva para as pessoas que causaram o problema), pensamentos fantasiosos e irrealistas voltados para a solução mágica do problema (Ex: Penso em coisas fantásticas ou irreais que me fazem sentir melhor), bem como respostas de esquiva (Ex: Procuro me afastar das pessoas em geral; Eu me recuso a acreditar que isto esteja acontecendo). Inclui ainda reações de culpabilização de outra pessoa (Ex: Eu culpo os outros) ou de si próprio (Ex: Eu me culpo) pelo aparecimento ou pelas consequiências do problema. Abarcam, portanto, estratégias cognitivas e comportamentais que podem cumprir função paliativa no enfrentamento e/ou resultar em afastamento do estressor.

O Fator 3 ( 7 itens; $\alpha=0,74 ; 5 \%$ de variância explicada) representa pensamentos e comportamentos religiosos que 


\section{E. M. F. Seidl \& Cols.}

Tabela 1. Solução fatorial com as cargas fatoriais, comunalidades, percentual de variância e alphas de Cronbach da Escala Modos de Enfrentamento de Problemas.

\begin{tabular}{|c|c|c|c|c|c|}
\hline \multirow{2}{*}{ Itens } & \multicolumn{4}{|c|}{ Fatores } & \multirow{2}{*}{$\mathbf{h}^{2}$} \\
\hline & 1 & 2 & 3 & 4 & \\
\hline Eu digo a mim mesmo o quanto já consegui & 0,62 & & & & 0,481 \\
\hline Eu sairei dessa experiência melhor do que entrei nela & 0,59 & & & & 0,452 \\
\hline Eu tento não fechar portas atrás de mim. Tento deixar em aberto várias saídas para o problema & 0,57 & & & & 0,432 \\
\hline Encaro a situação por etapas, fazendo uma coisa de cada vez & 0,54 & & & & 0,413 \\
\hline Eu levo em conta o lado positivo das coisas & 0,51 & & & & 0,393 \\
\hline M udo alguma coisa para que as coisas acabem dando certo & 0,51 & & & & 0,387 \\
\hline Estou mudando me tornando uma pessoa mais experiente & 0,49 & & & & 0,361 \\
\hline Eu tento não agir tão precipitadamente ou seguir minha primeira idéia & 0,47 & & & & 0,304 \\
\hline Eu fiz um plano de ação para resolver o meu problema e o estou cumprindo & 0,46 & & & & 0,378 \\
\hline Eu sei o que deve ser feito e estou aumentando meus esforços para ser bem sucedido & 0,44 & & & & 0,372 \\
\hline Eu me concentro nas coisas boas da minha vida & 0,44 & & & & 0,406 \\
\hline Eu insisto e luto pelo que eu quero & 0,43 & & & & 0,383 \\
\hline Eu me concentro em al guma coisa boa que pode vir desta situação & 0,42 & & & & 0,333 \\
\hline Tento ser uma pessoa mais forte e otimista & 0,40 & & & & 0,323 \\
\hline Eu fico me lembrando que as coisas poderiam ser piores & 0,39 & & & & 0,348 \\
\hline A ceito a simpatia e a compreensão de al guém & 0,39 & & & & 0,316 \\
\hline Encontro diferentes soluções para o meu problema & 0,38 & & & & 0,245 \\
\hline Eu tento evitar que os meus sentimentos atrapal hem em outras coisas na minha vida & 0,35 & & & & 0,311 \\
\hline Eu culpo os outros & & 0,59 & & & 0,436 \\
\hline Demonstro raiva para as pessoas que causaram o problema & & 0,55 & & & 0,432 \\
\hline Desconto em outras pessoas & & 0,55 & & & 0,418 \\
\hline Eu acho que as pessoas foram injustas comigo & & 0,50 & & & 0,395 \\
\hline $\begin{array}{l}\text { Penso em coisas fantásticas ou irreais (como uma vingança perfeita ou achar muito dinheiro) } \\
\text { que me fazem sentir melhor }\end{array}$ & & 0,49 & & & 0,346 \\
\hline Eu me sinto mal por não ter podido evitar o problema & & 0,48 & & & 0,480 \\
\hline Eu imagino e tenho desejos sobre como as coisas poderiam acontecer & & 0,45 & & & 0,440 \\
\hline Eu me culpo & & 0,45 & & & 0,340 \\
\hline Procuro um culpado para a situação & & 0,44 & & & 0,288 \\
\hline Eu percebo que eu mesmo trouxe o problema para mim & & 0,44 & & & 0,400 \\
\hline Procuro me afastar das pessoas em geral & & 0,44 & & & 0,345 \\
\hline Descubro quem mais é ou foi responsável & & 0,44 & & & 0,381 \\
\hline Eu brigo comigo mesmo; eu fico falando comigo mesmo o que devo fazer & & 0,43 & & & 0,317 \\
\hline Eu desejaria mudar o modo como eu me sinto & & 0,39 & & & 0,404 \\
\hline Eu me recuso a acreditar que isto esteja acontecendo & & 0,37 & & & 0,349 \\
\hline Eu me apego à minha fé para superar esta situação & & & 0,66 & & 0,547 \\
\hline Espero que um milagre aconteça & & & 0,54 & & 0,383 \\
\hline Pratico mais a religião desde que tenho esse problema & & & 0,51 & & 0,444 \\
\hline Eu desejaria poder mudar o que aconteceu comigo & & & 0,51 & & 0,470 \\
\hline Tento esquecer o problema todo & & & 0,51 & & 0,417 \\
\hline Eu rezo / oro & & & 0,49 & & 0,383 \\
\hline Eu sonho ou imagino um tempo melhor do que aquele em que estou & & & 0,35 & & 0,426 \\
\hline Converso com alguém sobre como estou me sentindo & & & & 0,67 & 0,457 \\
\hline Converso com alguém que possa fazer alguma coisa para resolver o meu problema & & & & 0,65 & 0,507 \\
\hline Converso com al guém para obter informações sobre a situação & & & & 0,53 & 0,495 \\
\hline Peço consel ho a um parente ou a um amigo que eu respeite & & & & 0,46 & 0,300 \\
\hline Eu tento guardar meus sentimentos para mim mesmo & & & & $-0,43$ & 0,295 \\
\hline Número de itens & 18 & 15 & 7 & 5 & \\
\hline \% de variância explicada & 9,2 & 7,5 & 5,0 & 3,9 & \\
\hline Alpha de Cronbach & 0,84 & 0,81 & 0,74 & 0,70 & \\
\hline
\end{tabular}

Fator 1. Estratégias de enfrentamento focalizadas no problema. Fator 2: Estratégias de enfrentamento focalizadas na emoção. Fator 3: Práticas religiosas/ Pensamento fantasioso. Fator 4: Busca de suporte social. 
possam auxiliar no enfrentamento do problema (Ex: Eu rezo/ oro). Aos itens originais do fator religiosidade, agregaramse os itens "espero que um milagre aconteça" (pensamento fantasioso/desiderativo), "eu desejaria poder mudar o que aconteceu comigo" (pensamento fantasioso/desiderativo), "eu sonho ou imagino um tempo melhor do que aquele em que estou" (pensamento fantasioso/desiderativo) e "tento esquecer o problema todo" (esquiva). A análise de significado do conjunto dos três primeiros itens aponta coerência com pensamentos fantasiosos permeados por sentimentos de esperança e fé.

O item "tento esquecer o problema todo", que representa uma postura de esquiva da situação no plano cognitivo, foi analisado no sentido de que ações religiosas ou místicas poderiam auxiliar no afastamento do problema da mente, pois pensamentos voltados para a fé poderiam predominar, reduzindo o pensamento voltado para a situação de estresse. Assim, devido ao significado comum aos outros itens do fator e à sua alta carga fatorial $(0,51)$, o item foi mantido no Fator 3. Optou-se por denominar o terceiro fator práticas religiosas/pensamento fantasioso.

O quarto fator, busca de suporte social ( 5 itens; $\alpha=0,70$; $3,9 \%$ de variância explicada), representa itens que têm como significado a procura de apoio instrumental, emocional ou de informação como estratégias de enfrentamento da situação causadora do estresse (Ex: Peço conselho a um parente ou a um amigo que eu respeite). Este fator agrupou os itens da escala original, mais o item classificado como esquiva "eu tento guardar meus sentimentos para mim mesmo". No entanto, este último item assumiu sentido negativo (carga igual a -0,43), o que é coerente com o significado de afastamento social em relação à expressão de sentimentos, estabelecendo sentido semântico com o fator.

A comparação das distribuições das médias dos escores em cada fator, obtidos nas duas sub-amostras, revelou características similares e algumas discrepâncias quanto às médias e desvios-padrão, medianas e curtose. Os resultados da comparação das médias, mediante o uso do teste t para amostras independentes, estão apresentados na Tabela 2. A amostra cujo estressor foi o problema de saúde apresentou médias mais elevadas em relação às estratégias focalizadas no problema, práticas religiosas/pensamento fantasioso e busca de suporte social; apresentou, no entanto, média menor do que a sub-amostra A em estratégias focalizadas na emoção, sendo que todas as diferenças foram estatisticamente significativas. Observou-se que as estratégias focalizadas na emoção alcançaram escores mais baixos nas duas sub-amostras, indicando menor freqüência de utilização em comparação com as demais estratégias de enfrentamento.

Correlações entre as estratégias de enfrentamento e variáveis sócio-demográficas - idade e escolaridade - indicaram que apenas na sub-amostra A ocorreram associações significativas entre estratégias focalizadas no problema e as variáveis idade $(r=0,18 ; p<0,01)$ e escolaridade $(r=0,16$; $p<0,01)$. Assim, pessoas mais velhas e com maior nível de escolaridade obtiveram escores mais altos no uso de estratégias focalizadas no problema. Ainda na sub-amostra A, a
Tabela 2. Médias dos fatores da Escala Modos de Enfrentamento de Problemas segundo o tipo de estressor

\begin{tabular}{lccccc}
\hline \multirow{2}{*}{$\begin{array}{l}\text { Estratégias de } \\
\text { enfrentamento }\end{array}$} & $\begin{array}{c}\text { Estressor } \\
\text { geral } \\
\text { (N= 252) }\end{array}$ & \multicolumn{2}{c}{$\begin{array}{c}\text { Estressor } \\
\text { de saúde } \\
\text { (N = 157) }\end{array}$} & t \\
\cline { 2 - 5 } & $\mathbf{M}$ & $\mathbf{D P}$ & $\mathbf{M}$ & $\mathbf{D P}$ & \\
\hline Focalização no problema & 3,52 & 0,58 & 3,68 & 0,59 & $-2,68 *$ \\
Focalização na emoção & 2,61 & 0,59 & 2,22 & 0,64 & $6,18^{* *}$ \\
$\begin{array}{l}\text { Práticas religiosas/pensamento } \\
\text { fantasioso }\end{array}$ & 3,20 & 0,79 & 3,50 & 0,86 & $-3,59 * *$ \\
Busca de suporte social & 3,33 & 0,79 & 3,62 & 0,67 & $-3,82^{* *}$ \\
\hline
\end{tabular}

** $p<0,001 \quad * p<0,01$

variável idade apresentou associação inversa com estratégias focalizadas na emoção $(r=-0,28 ; p<0,01)$, indicando que pessoas mais jovens parecem lançar mão dessa modalidade de enfrentamento (Tabela 3).

Quanto a práticas religiosas/pensamento fantasioso, ocorreu uma correlação negativa com escolaridade (A: $r=-0,25$; $p<0,001$; B: $r=-0,51 ; p<0,001)$, permitindo concluir que quanto menor o nível de escolaridade maior o enfrentamento com base na práticas religiosas/pensamento fantasioso, nas duas amostras estudadas (Tabelas 3 e 4). Este dado foi confirmado pela comparação dos escores médios das estratégias de enfrentamento, dividindo o total de participantes em dois grupos: escolaridade baixa (de $1^{\circ}$ grau incompleto até $2^{\circ}$ grau incompleto) e escolaridade alta (a partir de $2^{\circ}$ grau completo). Houve diferença apenas em relação à utilização da estratégia práticas religiosas/pensamento fantasioso, sendo que as pessoas de menor escolaridade tenderam a lançar usar mais essa estratégia, independente do estressor $(t=7,49 ; p<$ 0,001).

A análise por gênero, agregando homens e mulheres das duas sub-amostras, mostrou diferença significativa no uso das estratégias de enfrentamento apenas em relação a práticas religiosas/pensamento fantasioso, indicando que as mulheres, independente do tipo de estressor, lançaram mão dessa estratégia com maior frequiência $(t=-4,09 ; p<0,001)$. Nas outras estratégias de enfrentamento, não se verificou diferença significativa.

Nas correlações entre as estratégias de enfrentamento, verificou-se que, nas duas amostras, a associação entre estratégia de enfrentamento orientada para o problema com o enfrentamento na emoção foi quase nula (sub-amostra A/ estressor geral: $r=0,052$; sub-amostra B/estressor de saúde: $r=-0,054)$, indicando a independência desses dois conjuntos de estratégias nas amostras estudadas.

As estratégias orientadas para o problema apresentaram correlação positiva estatisticamente significativa com práticas religiosas/pensamento fantasioso (A: $r=0,22 ; p<0,001$; B: $r=0,27 ; p<0,001)$ e com busca de suporte social (A: $r=$ $0,27 ; p<0,001 ; \mathrm{B}: r=0,39 ; p<0,001)$, indicando que essas estratégias parecem cumprir funções complementares no enfrentamento do estresse e que as pessoas lançaram mão de estratégias diversas para lidar com estressores (Tabelas 3 e 4).

Práticas religiosas/pensamento fantasioso também esteve correlacionada com estratégias focalizadas na emoção (A: 
Tabela 3. Correlações entre os fatores da Escala Modos de Enfrentamento de Problemas e as variáveis idade e escolaridade, na sub-amostra A, estressor geral $(N=252)$.

\begin{tabular}{|c|c|c|c|c|}
\hline Variáveis & $\begin{array}{c}\text { Estratégias } \\
\text { focalizadas no } \\
\text { problema }\end{array}$ & $\begin{array}{c}\text { Estratégias } \\
\text { focalizadas na emoção }\end{array}$ & $\begin{array}{c}\text { Práticas religiosas/ } \\
\text { pensamento fantasioso }\end{array}$ & $\begin{array}{c}\text { Busca de } \\
\text { suporte social }\end{array}$ \\
\hline Estratégias focalizadas no problema & - & & & \\
\hline Estratégias focalizadas na emoção & 0,05 & - & & \\
\hline Práticas religiosas/ Pensamento fantasioso & $0,22 * *$ & $0,35^{* *}$ & - & \\
\hline Busca de suporte social & $0,27 * *$ & 0,05 & 0,09 & - \\
\hline Escolaridade & $0,18^{*}$ & 0,05 & $-0,25^{* *}$ & 0,11 \\
\hline Idade & $0,16 *$ & $-0,28 * *$ & $-0,04$ & $-0,01$ \\
\hline
\end{tabular}

$* * p<0,001 \quad * p<0,01$

Tabela 4. Correlações entre os fatores da Escala Modos de Enfrentamento de Problemas e as variáveis idade e escolaridade, na sub-amostra B, estressor problema de saúde $(N=157)$.

\begin{tabular}{|c|c|c|c|c|}
\hline Variáveis & $\begin{array}{c}\text { Estratégias } \\
\text { focalizadas no } \\
\text { problema }\end{array}$ & $\begin{array}{c}\text { Estratégias } \\
\text { focalizadas na emoção }\end{array}$ & $\begin{array}{l}\text { Práticas religiosas/ } \\
\text { pensamento fantasioso }\end{array}$ & $\begin{array}{c}\text { Busca de } \\
\text { suporte social }\end{array}$ \\
\hline Estratégias focalizadas no problema & - & & & \\
\hline Estratégias focalizadas na emoção & $-0,05$ & - & & \\
\hline Práticas religiosas/Pensamento fantasioso & $0,27 * *$ & $0,19 *$ & - & \\
\hline Busca de suporte social & $0,39 * *$ & 0,04 & $0,36 * *$ & - \\
\hline Escolaridade & 0,08 & $-0,09$ & $-0,51^{* *}$ & $-0,10$ \\
\hline Idade & 0,09 & 0,00 & 0,06 & 0,03 \\
\hline
\end{tabular}

$* * p<0,001 \quad * p<0,01$

$r=0,35 ; p<0,001 ; \mathrm{B}: r=0,19 ; p<0,01)$ nas duas subamostras. Na sub-amostra B, práticas religiosas/pensamento fantasioso apresentou ainda associação com suporte social $(r=0,36 ; p<0,001)$.

As respostas dadas à questão aberta, opcional, que indagava se a pessoa estaria utilizando outras formas de enfrentamento para lidar com a situação, foram categorizadas. Do total de pessoas que responderam à questão $(N=243), 41,5 \%$ indicaram exemplos de estratégias que foram classificadas como focalizadas no problema. Em seguida apareceram aquelas categorizadas como práticas religiosas $(6,4 \%)$. As estratégias focalizadas na emoção, com ênfase em esquiva, vieram a seguir $(2,9 \%)$. Em menor freqüência foram mencionadas estratégias categorizadas como resignação/ passividade $(2,4 \%)$, distração e diversão $(2,1 \%)$, busca de suporte social $(1,9 \%)$ e estratégias múltiplas $(0,7 \%)$.

\section{Discussão}

Os resultados obtidos na presente investigação apontam tanto para aspectos positivos quanto para aspectos negativos da versão brasileira da Escala Modos de Enfrentamento de Problemas (Vitaliano \& cols., 1985; Gimenes \& Queiroz, 1997). Quanto aos aspectos negativos, o número excessivo de itens excluídos da solução fatorial encontrada, assim como o baixo percentual de variância explicada, sinaliza deficiências na versão brasileira da EMEP. A simples tradução e adaptação da escala original talvez não seja suficiente para captar toda a riqueza e complexidade envolvida nas estratégias de enfrentamento voltadas para estressores específicos. Pesquisas futuras deverão introduzir novos itens, elaborados especialmente em função da teoria, visando a sua verdadeira adaptação à nossa realidade cultural.

No lado positivo, verifica-se que a versão final da EMEP apresenta uma estrutura fatorial razoavelmente coerente e significativa quando comparada com a literatura na área de enfrentamento. Alguns dos seus índices de associações com algumas variáveis sóciodemográficas e das estratégias de enfrentamento entre si, também seguiram o esperado, fornecendo bons indícios preliminares de sua validade.

A análise da estrutura fatorial nas duas sub-amostras, com a comparação dos respectivos resultados, também conta como ponto positivo dos achados quanto à capacidade psicométrica da EMEP. Verificou-se uma certa estabilidade na estrutura e natureza dos quatro fatores, independente do tipo de estressor ou de situação que estaria desencadeando as estratégias de enfrentamento (problema de saúde ou estressores como problemas financeiros, familiares, entre outros). Estruturas fatoriais com essas características são consideradas um desafio para alguns pesquisadores, tendo em vista a variedade das variáveis desencadeantes das respostas de enfrentamento e a diversidade das características sóciodemográficas das amostras (Amirkhan, 1994).

A estrutura fatorial encontrada, com o agrupamento de algumas sub-escalas do instrumento de Vitaliano e cols. (1985), levando à formação de dois fatores principais com- 
postos por itens que têm as mesmas funções no enfrentamento - focalização no problema e focalização na emoção tornou o instrumento mais parcimonioso. Outros instrumentos destinados a medir algumas das principais dimensões do enfrentamento têm mostrado uma tendência ao agrupamento dos fatores correspondentes às estratégias de enfrentamento focalizadas no problema ou na emoção, como o Coping Inventory for Stressful Situations - CISS (Endler \& Parker, 1999) e o Coping Strategies Indicator - CSI (Amirkhan, 1990), que também foram construídos com base em análise fatorial rigorosa.

Em relação ao CISS, que possui três fatores (enfrentamento orientado para a tarefa, enfrentamento orientado para a emoção e esquiva, este último sub-dividido em distração e diversão social), a análise semântica dos itens que compõem os seus dois primeiros fatores permite identificar muita semelhança com o significado das estratégias focalizadas no problema e na emoção do presente estudo. Uma diferença referese à busca de suporte social e práticas religiosas/pensamento fantasioso que não foram incluídos no instrumento canadense.

É possível identificar, ainda, semelhanças na estrutura fatorial da EMEP em relação aos fatores solução do problema e procura de suporte social do CSI. Em estudo de Clark e cols. (1995), a análise da intercorrelação entre fatores do CSI apontou associação entre solução do problema e procura de suporte social e ausência de associação entre esquiva e solução do problema e entre esquiva e suporte social, com resultados semelhantes aos do presente estudo. O fator esquiva do CSI, no entanto, parece limitado em relação ao conjunto de estratégias que poderiam representar estratégias focalizadas na emoção. É possível concluir que, não obstante os bons indicadores psicométricos, o CSI parece ser excessivamente parcimonioso e muito reduzido (possui 15 itens no total, cinco em cada fator), empobrecendo o conceito devido à redução das estratégias de enfrentamento focalizadas na emoção.

Práticas religiosas como estratégia de enfrentamento foi verificada em estudos anteriores, a partir de evidências quanto à importância da religião, em especial diante de situações difíceis (Carver \& cols., 1989; Vitaliano \& cols, 1985). O fator busca da religião da escala COPE alcançou o maior índice de consistência interna (alpha $=0,92)$ e esteve correlacionada positivamente com estratégias como enfrentamento ativo, planejamento, suporte social instrumental, suporte social emocional e reinterpretação positiva. Por outro lado, não apresentou associação significativa com estratégias focalizadas na emoção, exceto correlação negativa com negação. Clark e cols. (1995) verificaram que, além da associação com estratégias de enfrentamento focalizadas no problema, religião também esteve correlacionada moderadamente com ventilação de emoções, que representa a tendência de liberação de emoções relacionadas ao estresse e a sentimentos negativos, podendo apresentar caráter não adaptativo. Os achados permitem concluir que o enfrentamento relacionado à religião pode estar associado tanto a estratégias orientadas para o problema quanto a estratégias orientadas para a emoção, o que foi verificado no presente estudo.
O suporte social tem sido incluído em grande parte dos instrumentos para a mensuração do enfrentamento. Pesquisadores observaram que o apoio de pessoas significativas pode representar um papel importante em situações de estresse. Assim, Rodrígues-Marin e cols. (1992) encontraram correlação de 0,46 entre o fator busca de suporte social e busca de solução, enquanto houve associação negativa com repressão emocional. No presente estudo, busca de suporte social também apresentou associação com estratégias focalizadas no problema, nas duas amostras.

Os resultados referentes à maior utilização de estratégias focalizadas no problema, busca de suporte social e práticas religiosas/pensamento fantasioso, ao lado da menor utilização de estratégias focalizadas na emoção, pela amostra de pessoas cujo estressor foi problema de saúde, parece plausível, considerando que estas estavam adotando uma atitude de busca de cuidado de saúde (focalização no estressor), já que foram contatadas nos próprios serviços.

Quanto à busca da religiosidade diante de situações difíceis, em especial diante de problemas de saúde, estudos têm buscado elucidar questões relacionadas ao papel da religião e da espiritualidade no manejo do estresse em populações femininas (Biggar \& cols., 1999).

A pesquisa futura neste campo deve promover o aprofundamento da análise do enfrentamento em relação a variáveis sóciodemográficas e a alguns aspectos psicológicos tais como a associação entre características de personalidade e estratégias de enfrentamento (Shewchuk, Elliott, Macnair-Semands \& Harkins, 1999; Tróccoli, 1998). Pesquisadores têm defendido também a necessidade de estudos longitudinais, com análises estatísticas mais sofisticadas como a análise fatorial confirmatória, através dos modelos de equação estrutural (Endler, Parker \& Summerfeldt, 1993; Tróccoli, 1996).

\section{Referências}

Amirkhan, J.H. (1990). A factor analytically derived measure of coping: The coping strategy indicator. Journal of Personality and Social Psychology, 59,1066-1074.

Amirkhan, J.H. (1994). Criterion validity of a coping measure. Journal of Personality Assessment, 62, 242-261.

Biggar, H., Forehand, R., Devine, D., Brody, G., Armistead, L., Morse, E. \& Simon, P. (1999). Women who are HIV infected: The role of religious activity in psychosocial adjustment. Aids Care, 11, 195-199.

Carver, C.S., Scheier, M.F. \& Weintraub, J.K. (1989). Assessing coping strategies: A theoretically based approach. Journal of Personality and Social Psychology, 56, 267-283.

Clark, K.A., Bormann, C.A., Cropanzano, R.S. \& James, K. (1995). Validation evidence for three coping measures. Journal of Personality Assessment, 65, 434-455.

Endler, N.S. \& Parker, J.D.A. (1990). Multidimensional assessment of coping: A critical evaluation. Journal of Personality and Social Psychology, 58, 844-854.

Endler, N.S. \& Parker, J.D.A. (1999). Coping Inventory for Stressful Situations (CISS). Manual Second Edition. Toronto: MultiHealth Systems Inc. 
Endler, N.S., Parker, J.D.A. \& Summerfeldt, D. (1993). Coping with health problems: Conceptual and methodological issues. Canadian Journal of Behavioural Sciences, 25, 384-399.

Epstein, S. (1990). Cognitive-experiential self-theory. In L.A.Pervin (Ed.), Handbook of personality: Theory and research (pp. 165192). New York: The Guilford Press.

Ferrero, J., Barreto, M.P. \& Toledo, M. (1998). Estrés y salud. Em P.M. Martín, J.G. Martínez \& M.T. Aliaga (Orgs.), Intervención en psicología y salud (pp. 9-58). Valencia: Promolibro.

Folkman, S. (1984). Personal control and stress in coping processes: A theoretical analysis. Journal of Personality and Social Psychology, 46, 839-852.

Folkman, S. \& Lazarus, R.S. (1985). If it changes it must be a process: Study of emotion and coping during three stages of a college examination. Journal of Personality and Social Psychology, 50, 571-579.

Folkman, S., Lazarus, R.S., Gruen, R.J. \& De Longis, A. (1986). Appraisal, coping, health status and psychological symptons. Journal of Personality and Social Psychology, 50, 571-579.

Gimenes, M.G.G. (1997). A teoria do enfrentamento e suas implicações para sucessos e insucessos em psiconcologia. Em M.G.G. Gimenes \& M.H. Fávero (Orgs.), A mulher e o câncer (pp.111-147). Campinas: Editorial Psy.

Gimenes, M.G.G. \& Queiroz, B. (1997). As diferentes fases de enfrentamento durante o primeiro ano após a mastectomia. Em M.G.G. Gimenes \& M.H. Fávero (Orgs). A mulher e o câncer (pp. 171-195). Campinas: Editorial Psy.

Ingledew, D.K., Hardy, L., Cooper, C.L. \& Jemal, H. (1996). Health behaviours reported as coping strategies: A factor analytical study. British Journal of Health Psychology, 1, 263-282.

Kessler, R.C., Price, R.H. \& Wortman, C.B. (1985). Social factors in psychopathology: Stress, social support and coping processes. Annual Review Psychology, 36, 531-572.

Lazarus, R.S. (1982). Stress and coping as factors in health and illness. In J. Cohen (Org.), Psychosocial aspects of cancer. New York: Raven Press.

Ministério da Saúde. (1997). Conselho Nacional de Saúde. Diretrizes e normas para pesquisa envolvendo seres humanos. Resolução CNS 196/96. Brasília: Ministério da Saúde.

Nunes, C.M.P., Tróccoli, B.T., Tamayo, M.R. \& Pinheiro, F.A. (1999). Racionalidade e coping: correlações entre o Inventário do Pensamento Construtivo (CTI) e a forma abreviada do Inventário do Pensamento Racional vs. Experiencial (RVEI-S) [Resumo]. Em Sociedade Brasileira de Psicologia (Org.), Re sumos de comunicação científica. XXIX Reunião Anual de Psicologia (p. 236). Campinas: SBP.

Pinheiro, F.A., Tamayo, M.R., Tróccoli, B.T. (2000). Mensuração de coping no ambiente ocupacional: tradução e validação da Escala de Lateck. [Resumo] Em Sociedade Brasileira para o Progresso da Ciência (Org.), Anais da 52 ${ }^{\mathrm{a}}$ Reunião Anual da SBPC (p. 235). Brasília: SBPC.

Rodríguez-Marín, J., Terol, M.C., López-Roig, S. \& Pastor, M. (1992). Evaluación del afrontamiento del estrés: propriedades psicométricas del cuestionario de formas de afrontamiento de acontecimientos estresantes. Revista de Psicología de la Salud, 4, 59-82.
Shewchuk, R.M., Elliott, T.R., Macnair-Semands, R.R. \& Harkins, S. (1999). Trait influences on stress appraisal and coping: An evaluation of alternative frameworks. Journal of Applied Social Psychology, 29, 685-704.

Tabachnick, G.B. \& Fidell, L.S. (1996). Using multivariate statistics. New York: HarperCollins.

Thoits, P.A. (1995). Stress, coping and social support processes: Where are we? What next? Journal of Health and Social Behavior, Extra Issue, 53-79.

Tróccoli, B.T. (1996). Modelagem por equação estrutural: sua importância para a Psicologia da Saúde [Resumo]. Em Associação Brasileira de Psicologia Social (Org.), Anais do VI Encontro Regional Sul da ABRAPSO (p. 65). Universidade Federal de Santa Catarina: ABRAPSO.

Tróccoli, B.T. (1998). Pensamento experiencial vs. racional: mensuração e implicações. Relatório de Pesquisa. Universidade de Brasília.

Tróccoli, B.T. (no prelo-a). Heurísticos, viéses cognitivos e a percepção de risco. Em F.J.B. Albuquerque (Org.), Percepção de risco e sua relação com desastres naturais. João Pessoa, BR/Manitoba, CA: IDRC/UFPb.

Tróccoli, B.T. (no prelo-b). A teoria do self cognitivo-experiencial. Em M. Dela Coleta (Org.), Modelos psicossociais da saúde. São Paulo: Papirus.

Tróccoli, B.T., Nunes, C.M.P. \& Rodrigues, M.M.M. (1999). Pensamento experiencial e racional: mensurações e implicações [Resumo]. Em Sociedade Brasileira para o Progresso da Ciên-

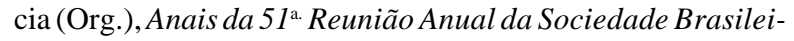
ra Para o Progresso da Ciência-SBPC (p. 193). Porto Alegre: SBPC.

Tróccoli, B.T., Laros, J.A.; Moraes, P.B., Hostensky, E.L. \& Araújo, R.M. (2000). Relações entre pensamento racional vs. experiencial e os cinco fatores de personalidade. [Resumo]. Em Sociedade Brasileira para o Progresso da Ciência (Org.), Anais da 52. Reunião Anual da SBPC (p. 214). Brasília: SBPC.

Vitaliano, P.P., Russo, J., Carr, J.E., Maiuro, R.D. \& Becker, J. (1985). The Ways of Coping Checklist: Revision and psychometric properties. Multivariate Behavioral Research, 20, 3-26.
Recebido em 26.07.2001

Aceito em 12.12.2001 